\title{
Chemical Modification of Potato Starch by Graft Copolymerization with Citronellyl Methacrylate
}

\author{
Marta Worzakowska ${ }^{1}$
}

Published online: 24 June 2017

(C) The Author(s) 2017. This article is an open access publication

\begin{abstract}
Chemical modification of potato starch with citronellyl methacrylate monomer, characterization of obtained materials and its physicochemical properties have been presented. The chemical modification of potato starch under the grafting process with citronellyl methacrylate led to the preparation of novel, amphiphilic materials where from 0.3 to ca. 1.6 hydroxyl groups per glycoside unit were replaced by poly(citronellyl methacrylate) chains. The grafting of poly(citronellyl methacrylate) chains onto starch backbone caused considerably changes in the morphology, polarity, solubility, chemical stability, moisture absorbance, gelatinization properties, thermal stability and decomposition mechanism of the prepared copolymers as compared to native potato starch. The influence of the grafting percent on the above mentioned properties as well as on the pyrolysis mechanism was discussed in detail.
\end{abstract}

Keywords Starch $\cdot$ Chemical modification - Citronellyl methacrylate $\cdot$ Properties

\section{Introduction}

Citronellol is a monoterpenoid, primary fragrant alcohol with sweet, agreeable, comparable with rose odour. It is found in the nature in some essential oils such as citronella oil which is raised from the stems and leaves of different species of Cymbopogon. The citronellol is also found in

Marta Worzakowska

marta.worzakowska@poczta.umcs.lublin.pl

1 Department of Polymer Chemistry, Faculty of Chemistry, Maria Curie-Skłodowska University, Gliniana 33 street, 20-614 Lublin, Poland rose oil, Eucalyptus citriodora, Boronia citriodora and Pelargonium geraniums oil. It can be obtained by the extraction or distillation from the plants or by the hydrogenation process of nerol or geraniol. According to the literature survey, this alcohol is commonly applied in the perfumery and cosmetic industries, it is added to candles, soups or incense as a source of flavor. Also, citronellol can be applied as a plant-based insect (mosquito) repellent, mite or pets attractant or antifungal agent. Due to the presence of the primary hydroxyl groups in it structure, it is used as a chemical for the production of rose oxide under the cycle of transformations including it photooxygenation to allyl hydroperoxide, it reduction with sodium sulfite to diol and finally diol ring-closure in the presence of sulfuric acid. Also, citronellol is used for the preparation of hydroxydihydrocitronellol and hydroxydihydrocitronellal [1-9]. It is useful reagent in the preparation of the aroma monoesters, diesters or tetraesters of acids and acid anhydrides. Monoesters of citronellol found their place as a fragrance or flavors added to many detergents, perfumes, medical products or laundry liquids. However, the diesters or tetraesters can be potential flavor compounds for different products or plasticizers for polymers [9-18]. Citronellol is also suitable reagent for the synthesis of it methacrylate ester under the lipase catalysed transestrification reaction using the following acylating agents: methyl methacrylate, vinyl methacrylate and 2,3-butanedione monooxime methacrylate [19]. The synthesis of citronellyl methacrylate with high yield can be performed under the amine catalysed reaction of citronellol with methacryloyl chloride according to Ref [20]. which is presented in this paper. This compound due to the presence of polymerizable double-double bonds in it structure can be useful monomer for the preparation of polymers and copolymers. 
This paper presents the utilization of citronellyl methacrylate prepared under the esterification process of naturally occurring terpene alcohol and methacryoyl chloride in the presence of triethylamine as a catalyst in the synthesis of copolymers with potato starch and the evaluation of the properties of the obtained materials. The copolymers were prepared under the free-radical graft copolymerization process of gelatinized potato starch with citronellyl methacrylate ester according to the procedure presented elsewhere [21-23]. By using this procedure, the series of novel copolymers which differ in its grafting parameters have been obtained. Their structure was confirmed based on the spectroscopic methods. The evaluation of the influence of the grafting parameters on the swelling, moisture absorbance, gelatinization, chemical stability in acid, alkaline and buffer solutions, thermal stability and its decomposition mechanism has been performed.

\section{Experimental}

\section{Materials}

Potato starch (amylopectin/amylose content: 83/17, purity 98\%) was isolated from potato flour containing $12 \%$ water (Melvit S.A., Poland) according to the procedure given in Ref [24]. Methacryloyl chloride (97\%), triethyloamine (99\%) were delivered by Sigma-Aldrich. Citronellol (95\%) was from Fluka, Switzerland. Chloroform, methanol, tetrahydrofurane, potassium persulfate and silica gel were obtained from Merck, Germany. Hydrochloric acid, sodium carbonate and buffer solutions were from POCh, Gliwice, Poland.

\section{Synthesis of Monomer}

The monomer was prepared and purified according to the procedure described elsewhere [20]. The esterification reaction of citronellol $(0.1 \mathrm{~mol})$ by methacryoyl chloride $(0.12 \mathrm{~mol})$ in the presence of a catalyst: triethylamine $(0.12 \mathrm{~mol})$ was performed, Fig. 1. As a solvent, chloroform $(150 \mathrm{~mL})$ was applied. The reaction at the temperature of $5{ }^{\circ} \mathrm{C}$ for $1 \mathrm{~h}$ and then at room temperature for the next $1 \mathrm{~h}$ was carried. The raw product was purified by washing with $10 \% \mathrm{HCl}, 1 \% \mathrm{Na}_{2} \mathrm{CO}_{3}$ and distilled water. After drying over $\mathrm{MgSO}_{4}$, the organic layer was cleaned using chromatographic colum filled with silica gel. As an eluent, chloroform was applied. The above reaction conditions allowed obtaining liquid, colorless monomer with high yield (95\%). The chemical structure of the monomer was confirmed based on the spectroscopic methods.

On the ATR-FTIR spectrum gathered for the monomer, the presence of the absorption signals characteristic for the out of plane deformation vibrations for $=\mathrm{C}-\mathrm{H}$ (755-1004 $\mathrm{cm}^{-1}$ ), the stretching vibrations for $\mathrm{C}=\mathrm{O}$ $\left(1035-1294 \mathrm{~cm}^{-1}\right)$, the deformation vibrations for $\mathrm{C}-\mathrm{H}$ (1375-1446 $\mathrm{cm}^{-1}$ ), the stretching vibrations for $\mathrm{C}=\mathrm{C}$ (1633 and $1672 \mathrm{~cm}^{-1}$ ), the stretching vibrations for $\mathrm{C}=\mathrm{O}\left(1716 \mathrm{~cm}^{-1}\right)$, the stretching vibrations for $\mathrm{C}-\mathrm{H}$ (2850-1958 $\left.\mathrm{cm}^{-1}\right)$ and the stretching vibrations for $=\mathrm{C}-\mathrm{H}\left(3020 \mathrm{~cm}^{-1}\right)$ has been identified [25]. The ${ }^{1} \mathrm{HNMR}$ spectrum shows the resonance signals responsible for the protons assigned to methacrylate carbon-carbon double bonds at 6.1 and at $5.5 \mathrm{ppm}$, for the proton attached to the citronellyl carbon-carbon double bond at $5.1 \mathrm{ppm}$, for the protons at $\mathrm{CH}_{2}-\mathrm{O}$ group at $4.2 \mathrm{ppm}$, for the protons at $\mathrm{CH}_{3}$ group near the methacrylate carbon-carbon double bond and for the $\mathrm{CH}_{2}$ group in the citronellyl skeleton at $2.0 \mathrm{ppm}$, for the protons at $\mathrm{CH}_{3}$ groups in the citronellyl skeleton at 1.6, 1.7 and $0.9 \mathrm{ppm}$, for the protons at $\mathrm{CH}_{2}$ groups and at $\mathrm{CH}$ group in the citronellyl skeleton at $1.2,1.3$ and $1.4 \mathrm{ppm}$. All resonance signals characteristic for carbons occurring in the monomer skeleton were also clearly visible from the presented ${ }^{13} \mathrm{CNMR}$ spectrum: at $167.6 \mathrm{ppm}(\mathrm{C}=\mathrm{O})$, at $136.6 \mathrm{ppm}(=\mathrm{C}<)$, at 131.4 $(=\mathrm{C}<)$, at $125.2 \mathrm{ppm}(=\mathrm{CH})$, at $124.7 \mathrm{ppm}\left(=\mathrm{CH}_{2}\right)$, at $63.3 \mathrm{ppm}\left(\mathrm{CH}_{2}\right)$, at $37.1 \mathrm{ppm}\left(\mathrm{CH}_{2}\right)$, at $35.5 \mathrm{ppm}\left(\mathrm{CH}_{2}\right)$, at $29.6 \mathrm{ppm}(\mathrm{CH})$, at $25.5 \mathrm{ppm}\left(\mathrm{CH}_{3}\right)$, at $19.6 \mathrm{ppm}\left(\mathrm{CH}_{3}\right)$, at $18.4 \mathrm{ppm}\left(\mathrm{CH}_{3}\right)$, at $17.7 \mathrm{ppm}\left(\mathrm{CH}_{3}\right)$ [26], Fig. 2.

\section{Graft Copolymerization}

The graft copolymerization process of potato starch with citronellyl methacrylate was performed according to the procedure described in Refs [21-23]. applying the following optimal reactions conditions: the temperature of $80^{\circ} \mathrm{C}$, reaction time of $2 \mathrm{~h}$, initiator concentration ( $2 \mathrm{wt} \%$ ) and the different potato starch to monomer ratio (from 1:0.25 up to 1:2.0).

The grafting parameters: grafting efficiency (\%GE), grafting percent $(\% \mathrm{G})$ and homopolymer percent $(\% \mathrm{H})$ were counted based on the following equations [27-29]:

$\% \mathrm{GE}=\mathrm{m}_{3} /\left(\mathrm{m}_{3}+\mathrm{m}_{2}\right) \times 100 \%$

where $m_{2}$ is the mass of homopolymer, $m_{3}$ is the mass of grafted polymer

$\% \mathrm{G}=\mathrm{m}_{3} / \mathrm{m}_{1} \times 100 \%$

where $m_{1}$ is the mass of starch, $m_{3}$ is the mass of grafted polymer

$\% \mathrm{H}=\mathrm{m}_{2} / \mathrm{m}_{0} \times 100 \%$

where $\mathrm{m}_{2}$ is the mass of homopolymer, $\mathrm{m}_{0}$ is the mass of monomer charged. 


\section{Characterization of Copolymers}

FTIR spectra of copolymers by applying the Attenuated total reflectance-Fourier transform infrared spectroscopy (ATR-FTIR) technique on a Bruker Tensor 27 instrument, Germany equipped with diamond crystal, over a resolution of $4 \mathrm{~cm}^{-1}$ and wavenumber region of $600-4000 \mathrm{~cm}^{-1}$ have been collected.

Cross-polarisation magic angle spinning $\left({ }^{13} \mathrm{C} \mathrm{CP} /\right.$ MAS NMR) spectra using a Bruker Avance 300 MSL instrument, Germany over the resonance frequency of 75.5 $\mathrm{MHz}$ have been recorded.

Scanning electron microscopy (SEM) microphotografts using a high resolution, low vacuum SEM/FIB, the Quanta 3D FEG system, FEI company with a magnification of $3000 \times$ and $8000 \times$ have been done.

Water, ethanol, butanol, toluene, hexane and $\mathrm{CCl}_{4}$ were applied as solvents in order to evaluate the swellability coefficients $(B)$ of the obtained materials. The $B$ values were calculated by equilibrium swelling in chosen solvents, using the centrifugation method based on a below equation [30]:

$\mathrm{B}=\left(\mathrm{V}_{1}-\mathrm{V}_{0}\right) / \mathrm{V}_{0} \times 100 \%$

where $V_{1}$ is the volume of the copolymer after swelling, $V_{0}$ is the volume of the dried copolymer.

Percent moisture absorbance $(\% M)$ was evaluated according to the following equation [31]:

$\% \mathrm{M}=\left(\mathrm{m}_{2}-\mathrm{m}_{1}\right) / \mathrm{m}_{1} \times 100 \%$

$\mathrm{m}_{2}$ is the final mass of the sample (after moisture absorbance study), $\mathrm{m}_{1}$ is the initial mass of the sample (before moisture absorbance study).

In order to evaluate $\% M$, the ca. $100 \mathrm{mg}$ of the dried sample was placed in an exsiccator and exposured to the water vapour at $25^{\circ} \mathrm{C}$ for $24 \mathrm{~h}$ and then weighted.

To evaluate the gelatinization properties of the copolymers, ca. $3 \mathrm{mg}$ of the copolymer and ca. $6 \mathrm{mg}$ of water were mixted and put away at room temperature for $24 \mathrm{~h}$ to equlibrate. Then, the samples were heated in close aluminium pans between the temperature of $20-100^{\circ} \mathrm{C}$ with a heating rate of $10 \mathrm{~K} / \mathrm{min}$ under argon atmosphere (flow rate $20 \mathrm{~mL} / \mathrm{min}$ ) using DSC Phoenix 204 instrument, Netzsch, Germany [21].

The chemical resistance study of the obtained copolymers were evaluated in $1 \mathrm{M} \mathrm{HCl}, 1 \mathrm{M} \mathrm{NaOH}$ and buffers with $\mathrm{pH} 5,7,9$. The percent mass loss of the copolmers in the chosen solutions was calculated based on the below equation [32]:

$\% \mathrm{WL}=\left(\mathrm{m}_{1}-\mathrm{m}_{2}\right) / \mathrm{m}_{1} \times 100 \%$

where $m_{1}$ is the initial mass of the dried sample, $m_{2}$ is the final mass of the sample (after chemical resistance studies).

The thermal properties of the copolymers by applying STA F1 Jupiter instrument Netzsch, Germany were evaluated. The copolymers were heated in open $\mathrm{Al}_{2} \mathrm{O}_{3}$ with a heating rate of $10 \mathrm{~K} / \mathrm{min}$ from $40^{\circ} \mathrm{C}$ up to $1000^{\circ} \mathrm{C}$ under helium atmosphere (a flow rate of $40 \mathrm{~mL} / \mathrm{min}$ ) and a sample mass ca. $10 \mathrm{mg}$.

The decomposition mechanism of copolymers using FTIR spectroscopy coupled with STA F1 Jupiter instrument was evaluated. The gaseous FTIR spectra over the wavenymber range of $600-4000 \mathrm{~cm}^{-1}$ and a resolution of $4 \mathrm{~cm}^{-1}$ were gathered.

\section{Results and Discussion}

\section{Characterization of the Copolymers}

The scheme of the graft copolymerization process of citronellyl methacrylate monomer onto starch backbone is shown in Fig. 3. The grafting parameters obtained for the different starch to citronellyl methacrylate ratio are presented in Table 1.

The presence of the stretching vibrations for $-\mathrm{OH}$ groups above $3500 \mathrm{~cm}^{-1}$ on the ATR-FTIR spectrum and the counted $\% \mathrm{G}$ confirmed only partial substitution of hydroxyl groups of starch by poly(citronellyl methacrylate) chains. According to the calculated grafting percent $(\% \mathrm{G})$ from 0.3 to ca. 1.6 hydroxyl groups per glycoside unit were substituted by new groups. Figure 4 showed the FTIR spectrum for the examplary copolymer. It was well visible the presence of the stretching vibrations of $\mathrm{C}-\mathrm{H}$ at maxima centered from 2865 to $2950 \mathrm{~cm}^{-1}$, the stretching vibration of

Fig. 1 The synthesis scheme of the monomer

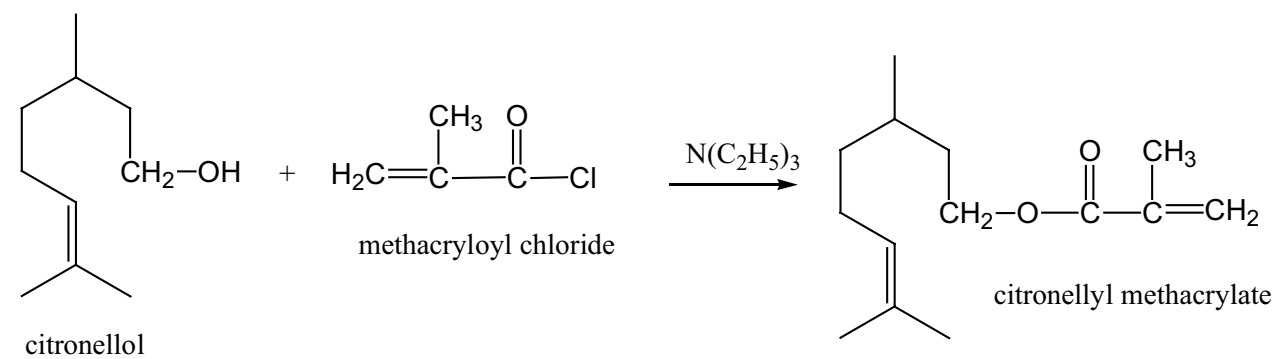



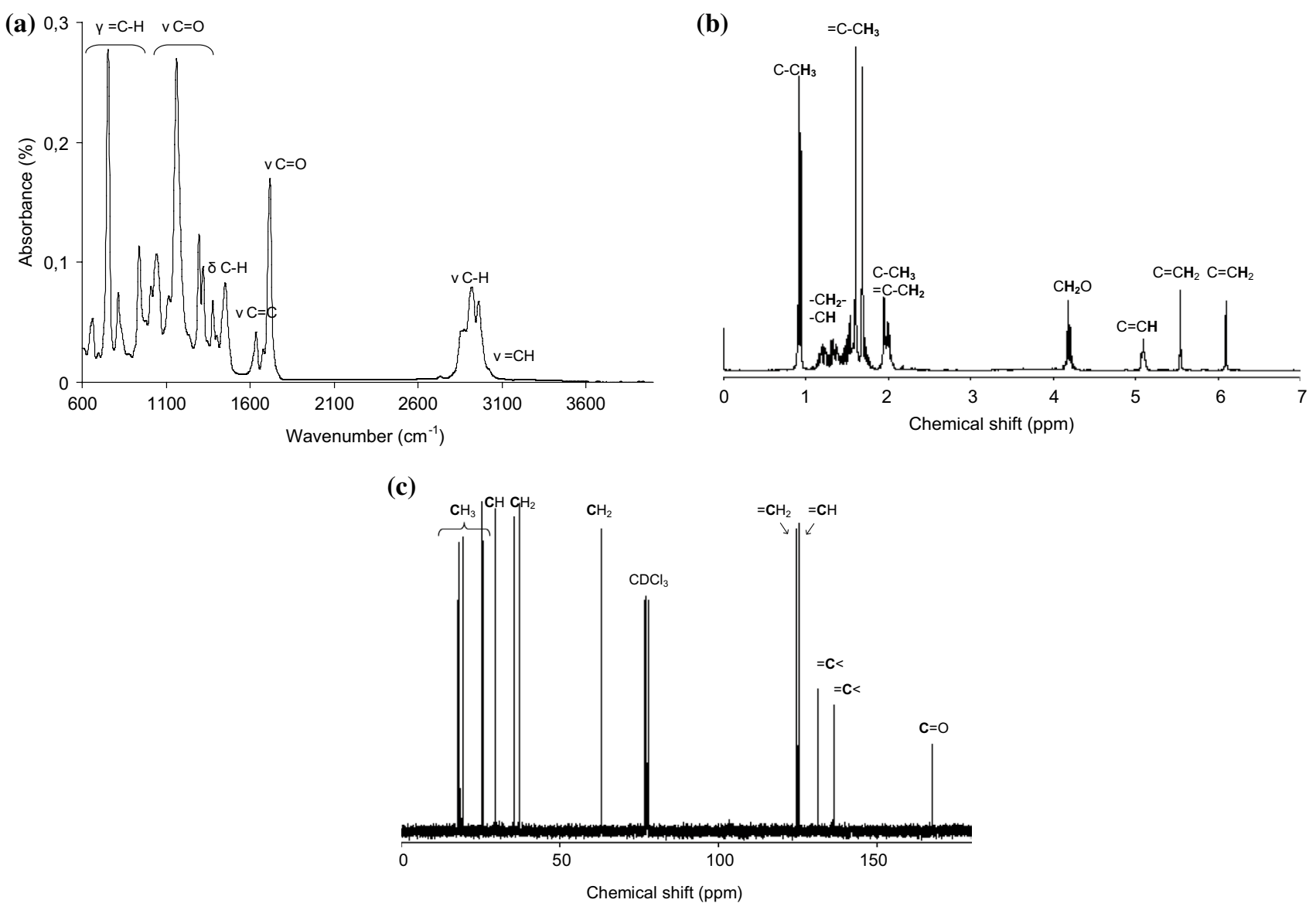

Fig. 2 Attenuated total reflectance-Fourier transform infrared (ATR-FTIR) spectra (a), proton nuclear magnetic resonance $\left({ }^{1} \mathrm{HNMR}\right)$ spectra $(\mathbf{b})$ and carbon-13 nuclear magnetic resonance $\left({ }^{13} \mathrm{CNMR}\right)$ spectra (c) for citronellyl methacrylate

$\mathrm{C}=\mathrm{O}$ at $1726 \mathrm{~cm}^{-1}$, two signals with maxima at $1370-1375$ and at $1445-1460 \mathrm{~cm}^{-1}$ which were characteristic for the deformation vibrations of $\mathrm{C}-\mathrm{H}$, the high intensity signals from 1000 to $1300 \mathrm{~cm}^{-1}$ responsible for the stretching vibrations of $\mathrm{C}-\mathrm{O}$ and the vibrations below $930 \mathrm{~cm}^{-1}$ which led to the presence of the skeletar vibrations of $\mathrm{C}-\mathrm{H}$ and the out-of-plane deformation vibrations of $=\mathrm{C}-\mathrm{H}$. The solid state NMR spectra also affirmed the structure of the copolymers. Besides the signals responsible for the carbon atoms present in the structure of starch from 6 to $102 \mathrm{ppm}$ (C1-C6), the appearance of the additional signals connecting with the presence of carbon atoms in $\mathrm{C}=\mathrm{O}$ groups at 175-177 ppm and the carbon atoms in $\mathrm{CH}, \mathrm{CH}_{2}$ and $\mathrm{CH}_{3}$ groups from 20 to $45 \mathrm{ppm}$ confirmed the formation of the desired product, (Fig. 4).

The SEM imagines showed that the morphology of the obtained materials differed considerably as compared to raw potato starch [21]. The incorporation of poly(citronellyl methacrylate) chains onto starch resulted in the destruction of starch grains and creation of irregular, connected, flap forms with concise but containing some cracks surface. Moreover, based on the SEM imagines it was noticed that as the grafting percent was increased the flaps were higher and more evident, (Fig. 5).

\section{Physicochemical Properties of Copolymers}

The swellability coefficient values for the obtained copolymers and raw potato starch in different solvents (polar: water, ethanol, butanol and non-polar: hexane, toluene and $\mathrm{CCl}_{4}$ ) were shown in Fig. 6a. The chemical modification of polar potato starch changed drastically the polarity of the copolymers which resulted in its lower swelling in polar solvents and its higher swelling in non-polar solvents as compared to unmodified potato starch [21, 22].

The chemical resistance of the obtained starch-gpoly(citronellyl methacrylate) copolymers in $1 \mathrm{M} \mathrm{HCl}, 1 \mathrm{M}$ $\mathrm{NaOH}$ and buffer solutions with the following pH 5, 7 and 9 has been studied. The studies indicated that the grafting of poly(citronellyl methacrylate) chains onto starch backbone caused considerably changes in the chemical stability of the prepared copolymers as compared to raw potato starch. In $1 \mathrm{M} \mathrm{NaOH}$ solution, the copolymers with lower grafting percent (copolymer 1 and copolymer 2) and raw 
Fig. 3 The sythesis scheme of starch-g-poly(citronellyl methacrylate) copolymers<smiles>C=C(C)C(=O)OCCC(C)CCC=C(C)C</smiles>

$\mathrm{K}_{2} \mathrm{~S}_{2} \mathrm{O}_{8}$, water

Temp.

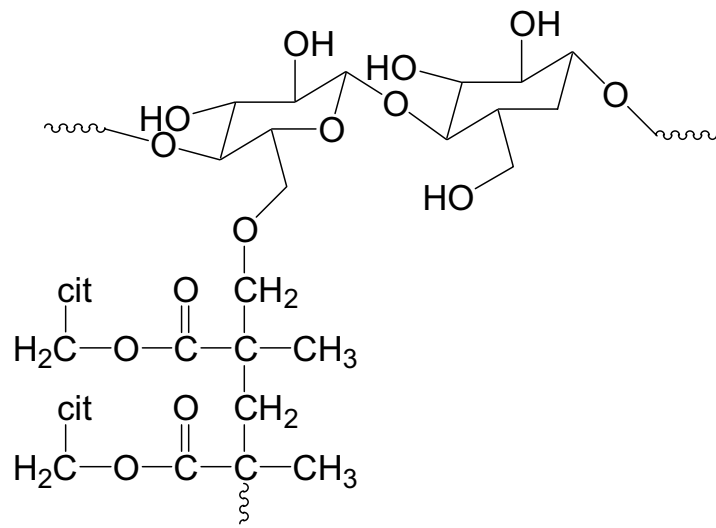

where: cit $=$<smiles>CC(C)=CCCC(C)C</smiles>

copolymer

Table 1 The grafting parameters

\begin{tabular}{llllr}
\hline Sample & $\begin{array}{l}\text { Starch:monomer } \\
\text { ratio }\end{array}$ & $\% \mathrm{GE}$ & $\% \mathrm{G}$ & $\% \mathrm{H}$ \\
\hline Copolymer 1 & $1: 0.25$ & $81.6 \pm 0.6$ & $10.5 \pm 0.3$ & $9.4 \pm 0.6$ \\
Copolymer 2 & $1: 0.5$ & $75.8 \pm 0.7$ & $15.8 \pm 0.2$ & $9.6 \pm 0.3$ \\
Copolymer 3 & $1: 0.75$ & $74.4 \pm 0.6$ & $21.3 \pm 0.4$ & $9.8 \pm 0.3$ \\
Copolymer 4 & $1: 1$ & $74.6 \pm 0.5$ & $25.6 \pm 0.4$ & $8.7 \pm 0.4$ \\
Copolymer 5 & $1: 1.5$ & $58.8 \pm 0.8$ & $37.0 \pm 0.2$ & $17.3 \pm 0.2$ \\
Copolymer 6 & $1: 1.75$ & $58.5 \pm 0.8$ & $49.7 \pm 0.3$ & $20.1 \pm 0.3$ \\
Copolymer 7 & $1: 2$ & $63.6 \pm 0.7$ & $51.8 \pm 0.3$ & $18.6 \pm 0.4$ \\
\hline
\end{tabular}

potato starch were fully degradated. However as the grafting percent was above $20 \%$, their chemical resistance in alkaline conditions significantly increased. Moreover, as it was cleary seen, the chemical resistance of the copolymers in all solutions was increased as the grafting percent increased. What was interesting was that the highest chemical stability of copolymers in buffer with $\mathrm{pH} 7$ was indicated, (Fig. 6b).

According to the results presented in Fig. 6c, the starch$g$-poly(citronellyl methacrylate) copolymers were characterized by considerably lower percent moisture absorbance than raw potato starch. The percent moisture absorbance for copolymer with the highest grafting percent (copolymer 7) was ca. 5 times lower as compared to potato starch. This was predictable situation since the introduction of hydrophobic poly(citronellyl metharylate) chains into the structure of starch resulted in obtaining more hydrophobic copolymers with concise, non-porous structure with not many cracks and thus lower absorption of hydrophilic nature moisture.

\section{Thermal Properties and Decomposition Mechanism of Copolymers}

On the TG/DTG curves, one can see several temerature ranges where the mass loss under the heating of starch- $g$ poly(citronellyl methacrylate) copolymers in inert conditions is observed, (Fig. 7). The first one was visible at $T_{\max 0}$ from ca. $81^{\circ} \mathrm{C}$ to ca. $130^{\circ} \mathrm{C}$. It was connected with small mass loss (0.1-2.8\%), (Table 2). It was due to the evaporation of moisture from the copolymers which was confirmed based on the FTIR analysis. On the gaseous FTIR spectra gathered at $T_{\max 0}$ the presence of the signals characteristic for water vapour visible as the "noises" at $1400-1700 \mathrm{~cm}^{-1}$ and at $3500-3900 \mathrm{~cm}^{-1}$ has been indicated [33], (Fig. 8). The second mass loss between the tempeartures of $140-215^{\circ} \mathrm{C}$ with $T_{\max 1}$ at $161-194^{\circ} \mathrm{C}$ for 
Fig. 4 Attenuated total reflectance-Fourier transform infrared spectroscopy (ATRFTIR) spectra for starch- $g$-copolymer and potato starch (a), Cross-polarisation magic angle spinning $\left({ }^{13} \mathrm{C} \mathrm{CP} / \mathrm{MAS}\right.$ NMR $)$ spectra for starch- $g$-copolymer and potato starch (b)

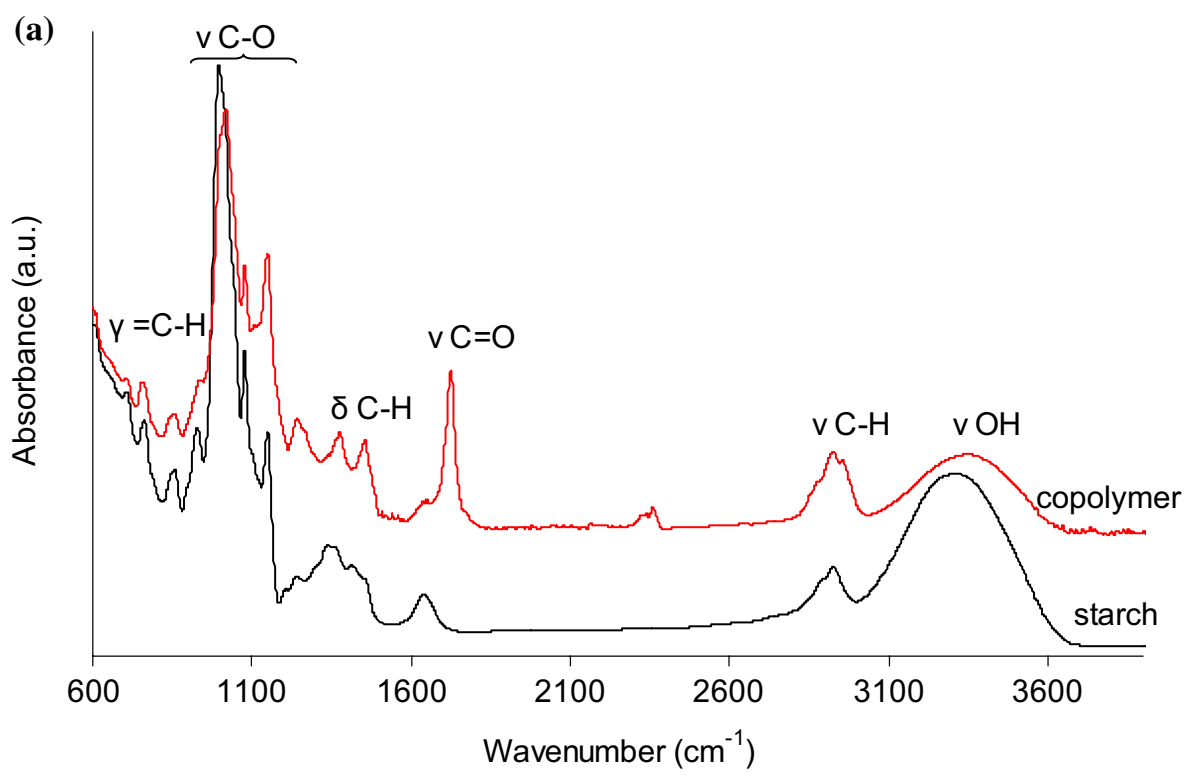

(b)

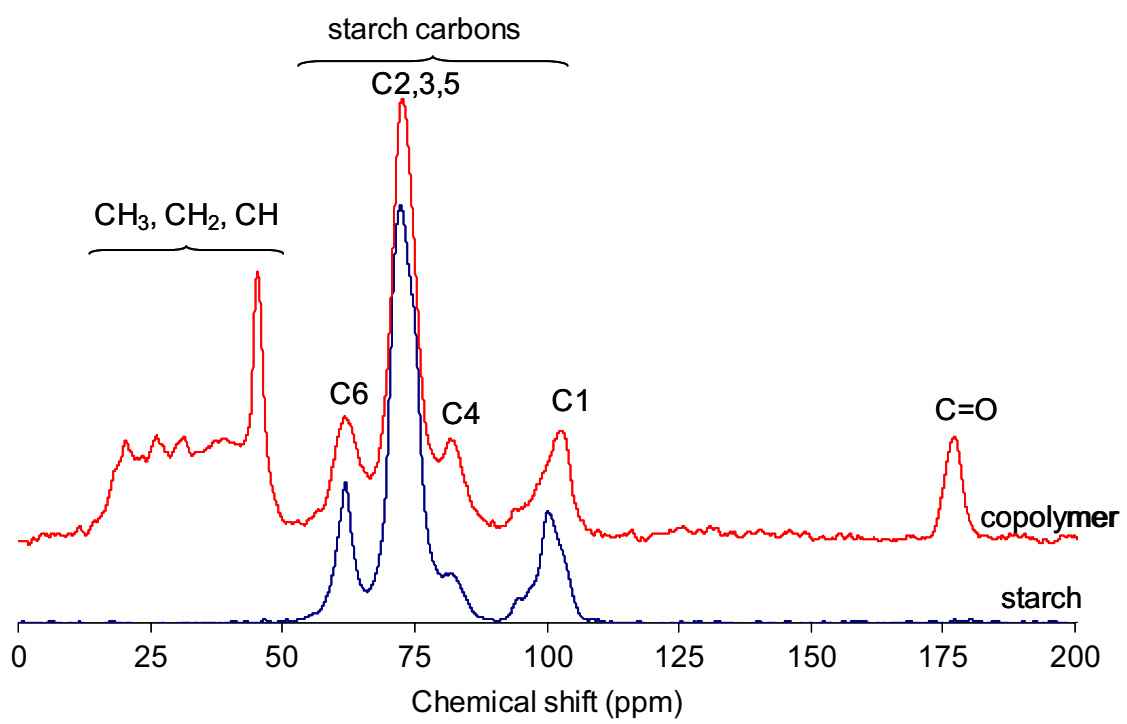

the majority of the copolymers (without copolymer 1) was appeared. In this stage, the beginning of the decomposition of copolymers was happened. The mass loss in this decomposition stage was from $2.9 \%$ up to $7.9 \%$. Analyzing the gaseous FTIR spectra gathered at $T_{\max 1}$, the presence of the absorption signals responsible for the stretching vibrations of $\mathrm{C}-\mathrm{H}$ at $2734-2977 \mathrm{~cm}^{-1}$, the small signal at $3068 \mathrm{~cm}^{-1}$ coming from the stretching vibrations of $=\mathrm{C}-\mathrm{H}$, the undivided signals at $1700-1790 \mathrm{~cm}^{-1}$ which were the result of the stretching vibrations characteristic for $\mathrm{C}=\mathrm{O}$ groups, the signal at $1643 \mathrm{~cm}^{-1}$ describing the stretching vibrations of $\mathrm{C}=\mathrm{C}$, the signals at $1508-1540 \mathrm{~cm}^{-1}$ responsible for the stretching vibrations of ring $\mathrm{C}=\mathrm{C}$, the small signals at the range of $1344-1470 \mathrm{~cm}^{-1}$ responsible for the deformation vibrations of $\mathrm{C}-\mathrm{H}$, the signals at $1066-1203 \mathrm{~cm}^{-1}$ characteristic for the stretching vibrations of $\mathrm{C}-\mathrm{O}$ and the signals with low intensity below the wavenumber of $900 \mathrm{~cm}^{-1}$ which were due to the out of plane deformation vibrations of $=\mathrm{C}-\mathrm{H}$ has been observed [33]. The occurrence of the above mentioned absorption signals on the FTIR spectrum indicated on long chain scissors and the emisssion of small amounths of aldehydes, alcohols, acids, aliphatics and furanes $[34,35]$.

The next decomposition stage of the copolymers run at the temperature range of ca. $215-320^{\circ} \mathrm{C}$ with $T_{\max 2}$ at $275-283{ }^{\circ} \mathrm{C}$. The mass loss was from $41.9 \%$ for copolymer 1 to $29.9 \%$ for copolymer 7 and it was decreased as the $\% \mathrm{G}$ increased. On the gaseous FTIR spectra collected at $T_{\max 2}$, the characteristic bands for water (above $\left.3500 \mathrm{~cm}^{-1}\right)$, carbon oxide $\left(2000-2200 \mathrm{~cm}^{-1}\right)$, carbon dioxide (2300-2352 $\left.\mathrm{cm}^{-1}\right)$, the stretching vibrations for C-H groups $\left(2730-2970 \mathrm{~cm}^{-1}\right)$, the stretching vibrations 

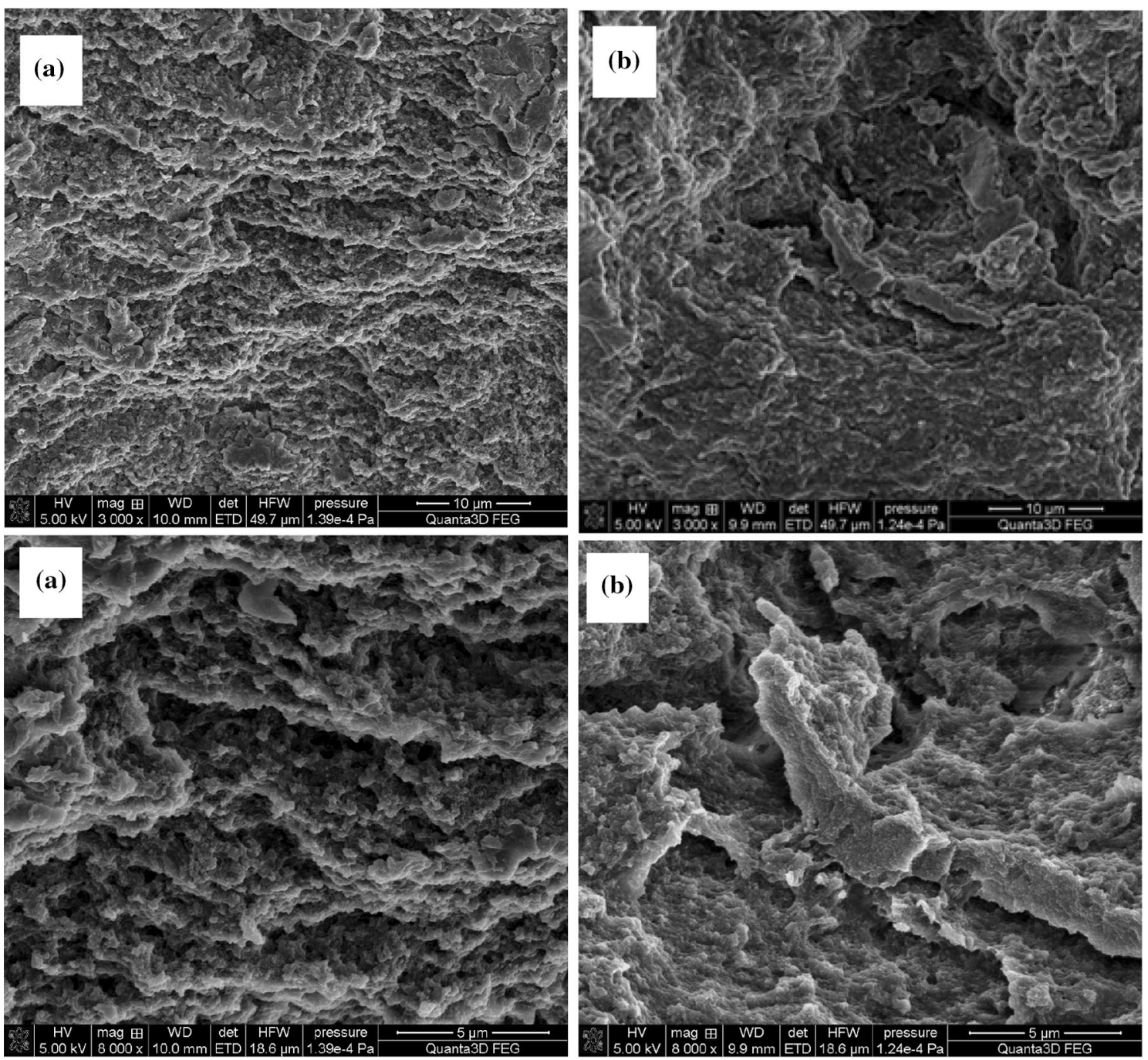

Fig. 5 Scanning electron microscopy (SEM) imagines for strach- $g$-poly (citronellyl methacrylate) copolymers: a grafting percent $(\% \mathrm{G})=21.3 \%$, b grafting percent $(\% \mathrm{G})=51.8 \%$ at magnification to $\times 3000$ and $\times 8000$

for $\mathrm{C}=\mathrm{O}\left(1700-1790 \mathrm{~cm}^{-1}\right)$, the stretching vibration for $\mathrm{C}=\mathrm{C}\left(1645 \mathrm{~cm}^{-1}\right)$, the stretching vibrations for $\mathrm{C}=\mathrm{C}$ at a ring (1510-1540 $\mathrm{cm}^{-1}$ ), the deformation vibrations for $\mathrm{C}-\mathrm{H}\left(1365-1450 \mathrm{~cm}^{-1}\right)$, the stretching vibrations for $\mathrm{C}-\mathrm{O}$ $\left(1070-1286 \mathrm{~cm}^{-1}\right)$ and the out of plane deformation vibrations for $=\mathrm{C}-\mathrm{H}\left(740-990 \mathrm{~cm}^{-1}\right)$ [33] which indictated on the emission of the mixture of gaseous decomposition products were appeared. Among them, the evolution of aldehyde, acids, alcohols, aliphatic, alkene and furanes fragments are the most expected as a result of the decomposition of starch from the copolymers. In addition, the presence on the gaseous FTIR spectra accumulated at $T_{\max 2}$ some of the bands indicated on the beginning of the emisssion of monomer: citronellyl methacrylate and some of alkene and acid as a result of the chain end depolymerization process of the grafted polymer and the decomposition of monomer. According to the studies performed in our Department, decomposition of pure poly(citronellyl methacrylate) was described by wide, assymetrical DTG peak which spread between the temperatures of ca. $250^{\circ} \mathrm{C}$ up to ca. $500^{\circ} \mathrm{C}$ with $T_{\max }$ ca. $396^{\circ} \mathrm{C}$. It confirmed that the depolymerization initiated at the end of polymer chain could happened under the second decomposition stage of copolymers.

The third decomposition stage which was not completely separated from the second decomposition stage was happened from the temperature of ca. $320^{\circ} \mathrm{C}$ to ca. $540^{\circ} \mathrm{C}$ with $T_{\max 3} 366-393^{\circ} \mathrm{C}$. The mass loss was from $23.4 \%$ up to $50.4 \%$ and it was increased as the $\% \mathrm{G}$ increased. It indicated that this decomposition stage was directly connected with the decomposition of the grafted poly(citronellyl methacrylate). This was confirmed based on the gathered FTIR spectra at $T_{\max 3}$. On the FTIR spectra, the occurrence of the bands characteristic for the stretching 
Fig. 6 Swellability coefficient (a), mass loss under the treating of the samples with $1 \mathrm{M} \mathrm{HCl}$, $1 \mathrm{M} \mathrm{NaOH}$ and buffer solutions (b), percent moisture absorbance (c)
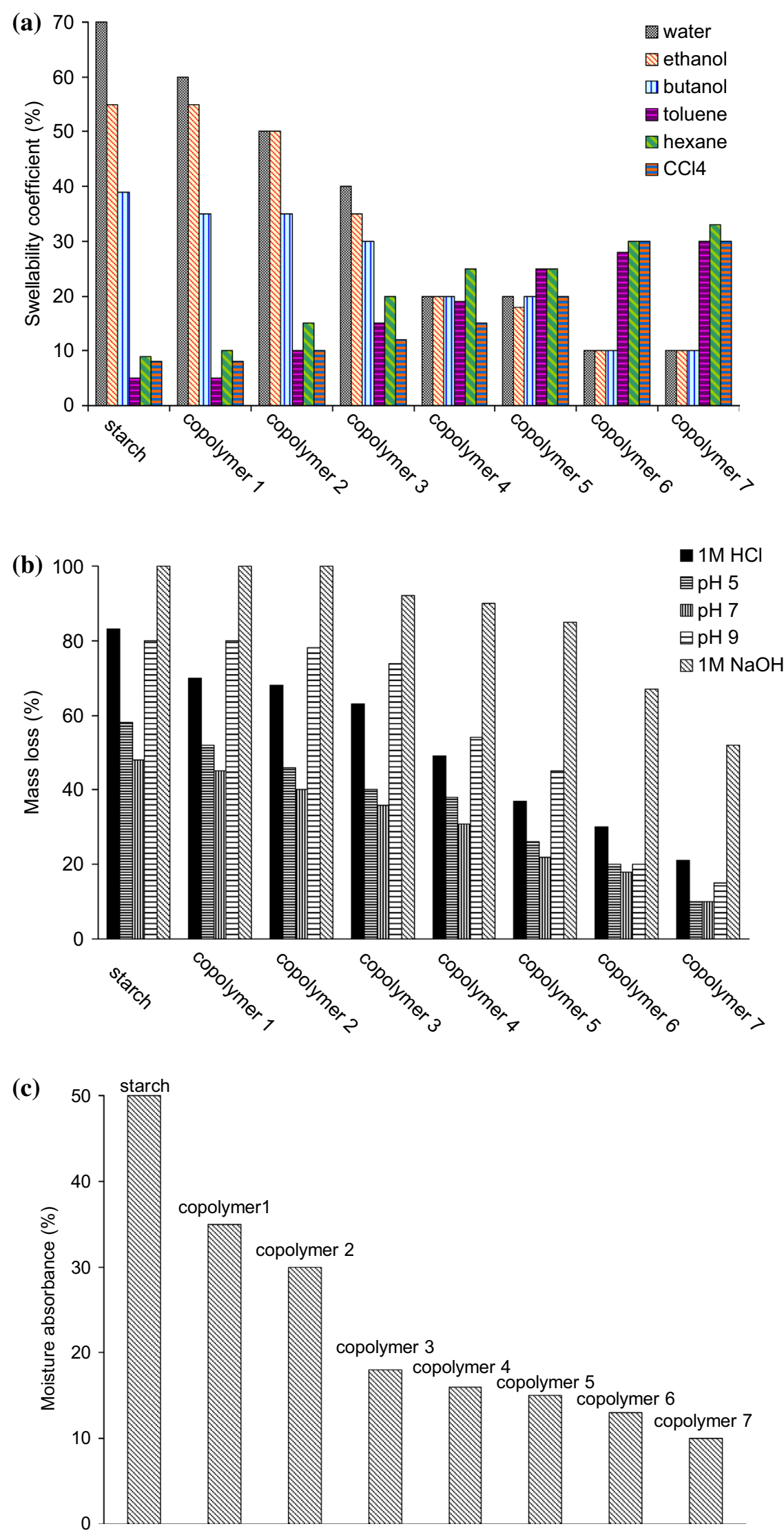
Fig. 7 Thermogarvimetric/ derivative thermogravimetric (TG/DTG) curves for copolymers
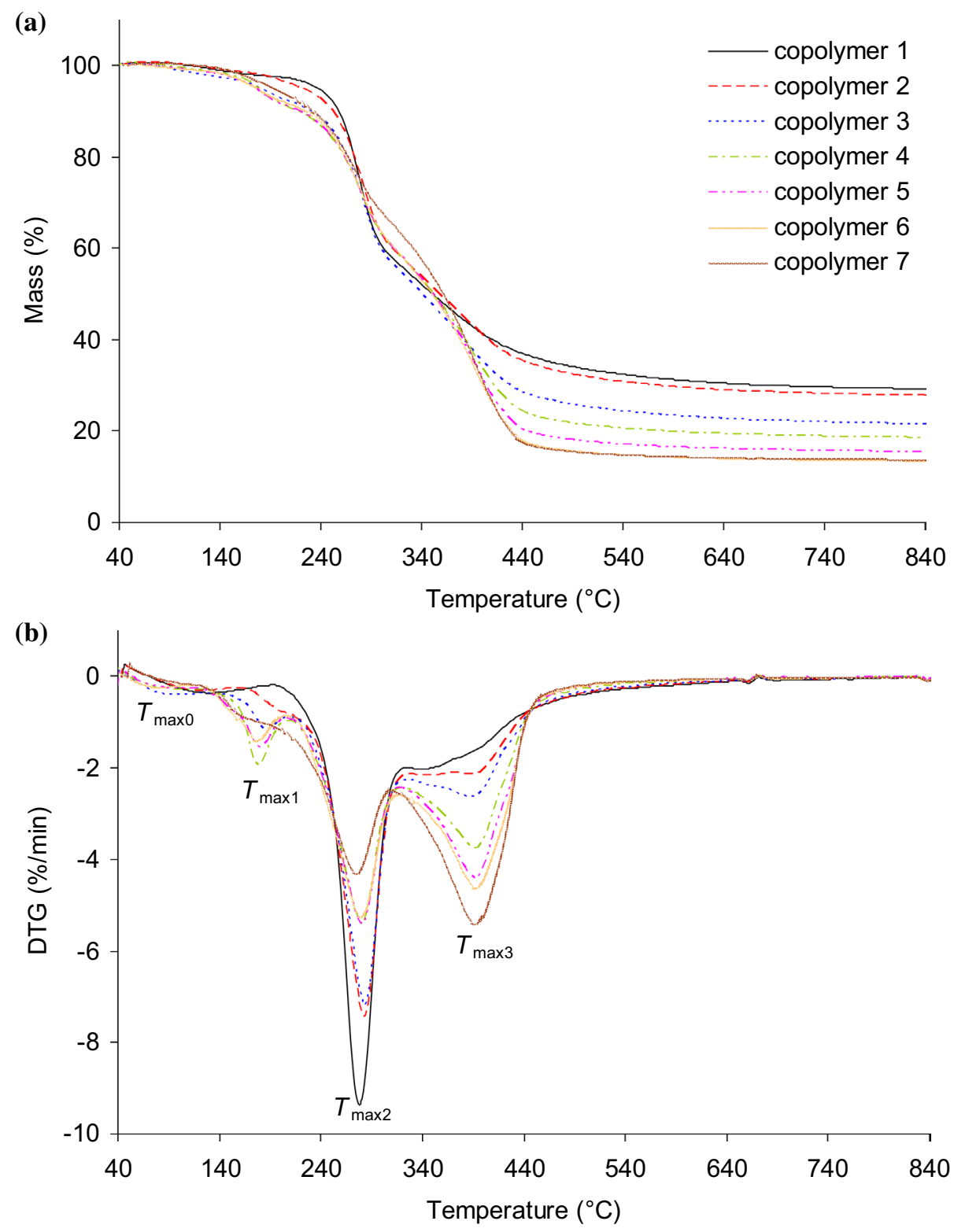

Table 2 Thermogarvimetric/derivative thermogravimetric (TG/DTG) data for the studied copolymers

\begin{tabular}{lllllllllll}
\hline Sample & $\mathrm{T}_{\max 0}\left({ }^{\circ} \mathrm{C}\right)$ & $\Delta_{\mathrm{m} 0}(\%)$ & $\mathrm{T}_{\max 1}\left({ }^{\circ} \mathrm{C}\right)$ & $\Delta_{\mathrm{m} 1}(\%)$ & $\mathrm{T}_{\max 2}\left({ }^{\circ} \mathrm{C}\right)$ & $\Delta_{\mathrm{m} 2}(\%)$ & $\mathrm{T}_{\max 3}\left({ }^{\circ} \mathrm{C}\right)$ & $\Delta_{\mathrm{m} 3}(\%)$ & $\Delta_{\mathrm{m} 4}(\%)$ & $\mathrm{rm}(\%)$ \\
\hline Copolymer1 & 130 & 2.5 & - & - & 278 & 41.9 & 366 & 23.4 & 2.9 & 29.3 \\
Copolymer2 & 115 & 1.6 & 194 & 2.9 & 283 & 39.3 & 392 & 25.9 & 2.8 & 27.5 \\
Copolymer3 & 96 & 2.8 & 185 & 5.2 & 282 & 38.6 & 390 & 29.6 & 2.6 & 21.2 \\
Copolymer4 & 88 & 1.4 & 176 & 7.9 & 280 & 32.9 & 392 & 37.6 & 2.0 & 18.2 \\
Copolymer5 & 89 & 1.4 & 178 & 7.6 & 281 & 32.6 & 393 & 41.5 & 1.6 & 15.3 \\
Copolymer6 & 81 & 1.0 & 178 & 7.3 & 280 & 33.3 & 392 & 43.6 & 1.4 & 13.4 \\
Copolymer7 & 100 & 0.1 & 161 & 5.0 & 275 & 29.9 & 392 & 50.4 & 1.1 & 13.5 \\
\hline
\end{tabular}

$\mathrm{T}_{\max 0}, \mathrm{~T}_{\max 1}, \mathrm{~T}_{\max 2}, \mathrm{~T}_{\max 3}$-maximum peak temperatures, $\Delta_{\mathrm{m} 0}, \Delta_{\mathrm{m} 1}, \Delta_{\mathrm{m} 2}, \Delta_{\mathrm{m} 3}, \Delta_{\mathrm{m} 4}$-mass loss, rm—residual mass at $850^{\circ} \mathrm{C}$ 
vibrations for $=\mathrm{C}-\mathrm{H}\left(3080 \mathrm{~cm}^{-1}\right)$, the stretching vibrations for $\mathrm{C}-\mathrm{H}\left(2879-2966 \mathrm{~cm}^{-1}\right)$, the stretching vibrations for $\mathrm{C}=\mathrm{O}\left(1700-1763 \mathrm{~cm}^{-1}\right)$, the stretching vibrations for $\mathrm{C}=\mathrm{C}\left(1645 \mathrm{~cm}^{-1}\right)$, the deformation vibrations for $\mathrm{C}-\mathrm{H}$ (1388 and $1460 \mathrm{~cm}^{-1}$ ), the stretching vibrations for $\mathrm{C}-\mathrm{O}$ $\left(1039-1290 \mathrm{~cm}^{-1}\right)$ and the out of plane deformation vibrations for $=\mathrm{C}-\mathrm{H}\left(802-910 \mathrm{~cm}^{-1}\right)$ indicated on the emission of monomer (citronellyl methacrylate) as a main decomposition product which was the result of the depolymerization process of grafted polymer. In addition, the double carbonyl signal, wide signal at $1030-1290 \mathrm{~cm}^{-1}$ and the emission of $\mathrm{CO}_{2}, \mathrm{CO}$ and $\mathrm{H}_{2} \mathrm{O}$ in this decomposition stage may indicate on the partial decarboxylation of the main product and the emission of some lower molecular mass compounds such as acids, aldehydes and alkenes as a result of the decomposition of monomer. Finally, at the temperatures above $540^{\circ} \mathrm{C}$, slow mass loss in the range of $2.9-1.1 \%$ was observed. At this decomposition stage, the main decomposition products were water and methane. It was affirmed based on the presence of the water bands $\left(1400-1700 \mathrm{~cm}^{-1}\right.$ and above $\left.3500 \mathrm{~cm}^{-1}\right)$ and methane band $\left(3014 \mathrm{~cm}^{-1}\right)$ [33] on the gaseous FTIR spectra. Aditionally, it was clearly visible that the methane band intensity was decreased as the grafting percent increased. It indicated that the amounth of methane created at this decompsoition stage could be connected and dependent on the presence of potato starch in the copolymers. According to the results presented in Table 2, the heating of the copolymers up to $850^{\circ} \mathrm{C}$ caused
Fig. 8 The selected gaseous Fourier transform infrared (FTIR) spectra for the studied copolymers
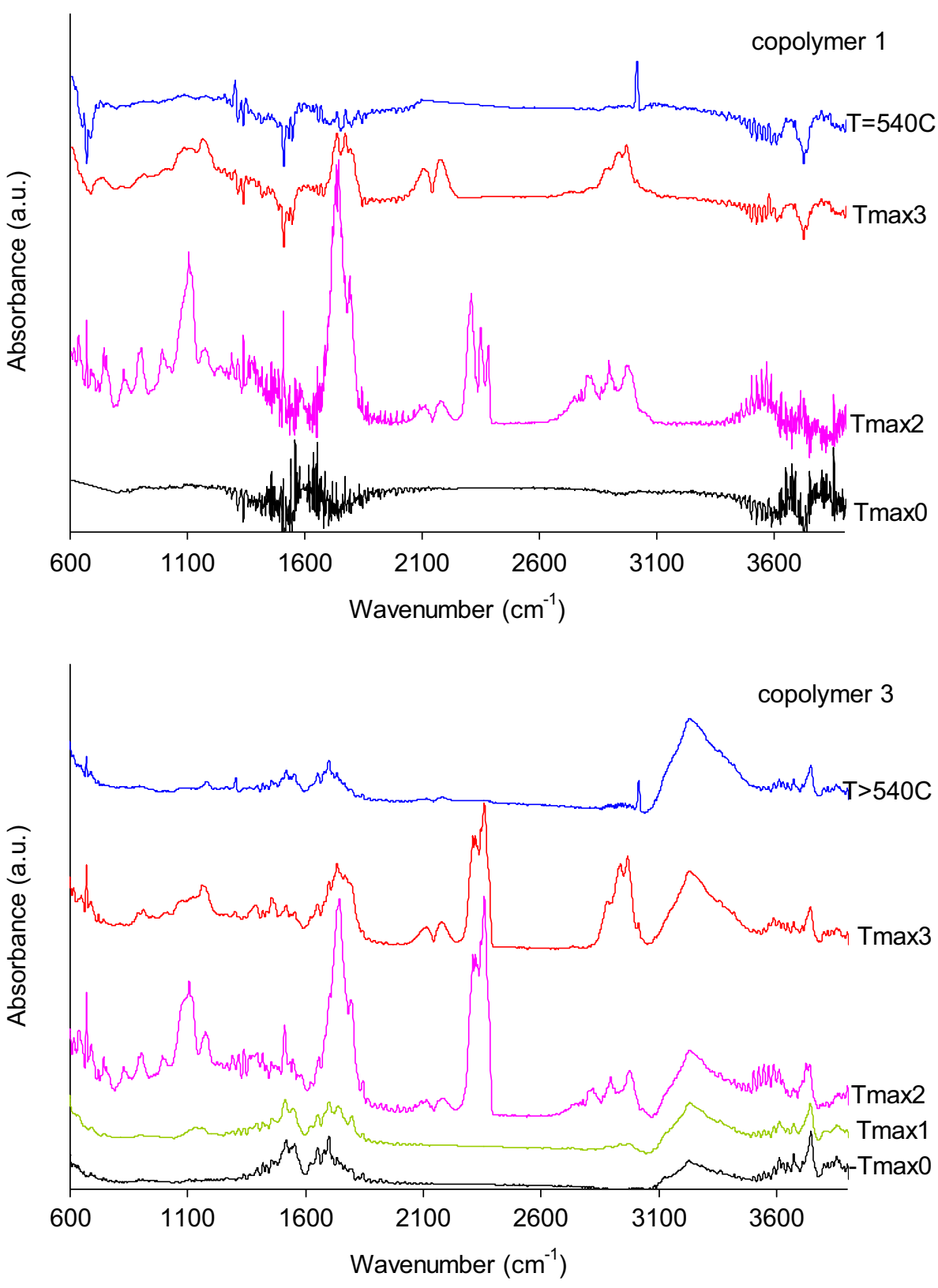
Fig. 8 (continued)
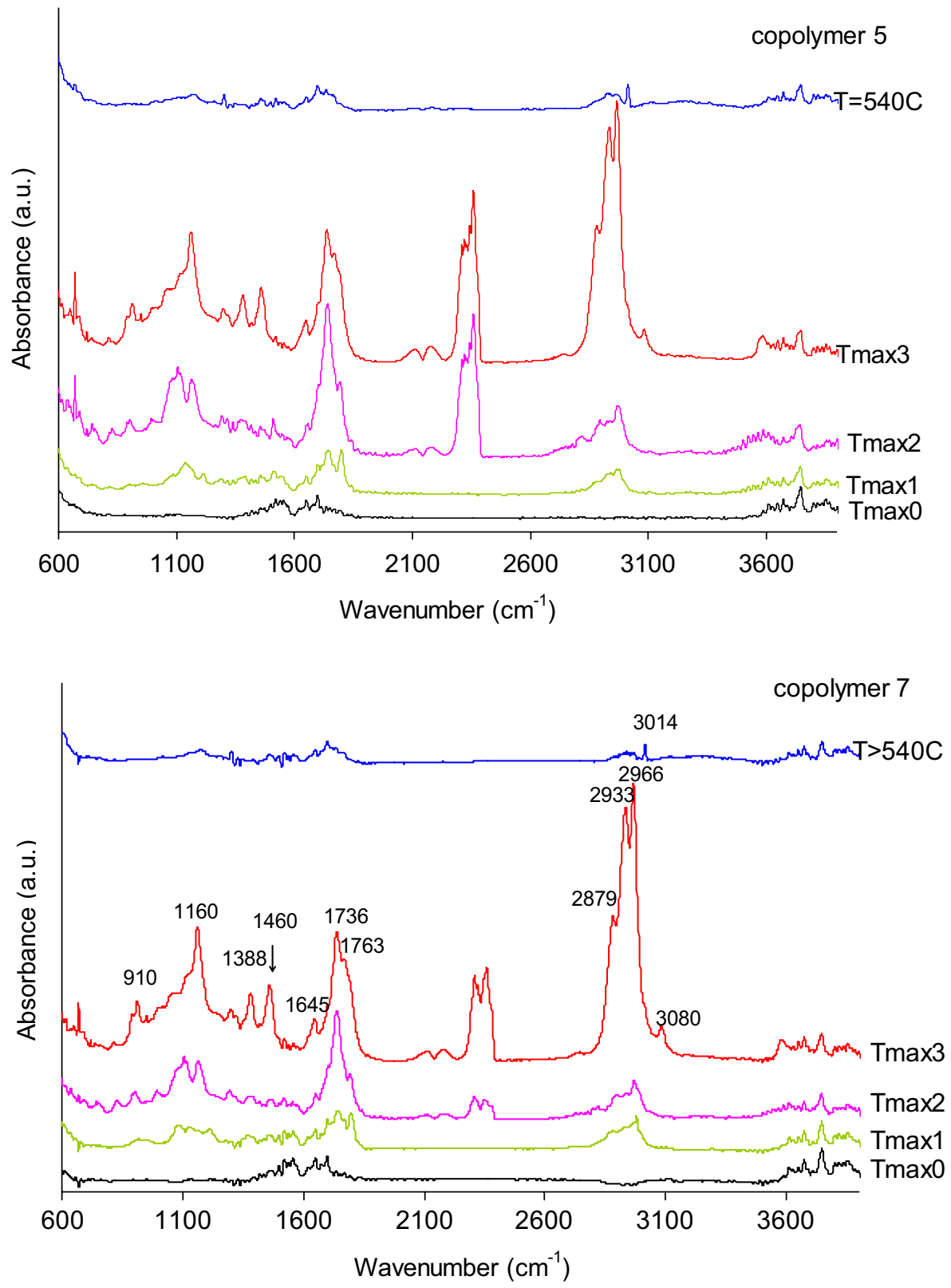

the formation of high char content (29.3-13.5\%). It proved that the starch- $g$-poly(citronellyl methacrylate) copolymers in particular those with lower grafting percent can be considered as potential precursors for the preparation of carbon materials $[36,37]$.

\section{Conclusions}

The chemical modification of potato starch with citronellyl methacrylate monomer under the grafting process allowed obtaining novel, more environmentally friendly with improved physicochemical properties and cheaper amphiphilic materials.
It was proved that the incorporation of poly(citronellyl methacrylate) chains onto starch resulted in the destruction of starch granules and creation of irregular, concise with some cracks surface. The chemical modification of potato starch with the hydrophobic polymer allowed producing the materials which were characterized by higher chemical stability towards acid, alkaline and buffers environment, higher moisture resistance, higher swelling in non-polar solvents, higher solvent resistance as compared to unmodified potato starch. Additionally, thermal decomposition process of copolymers happened at least four stages connecting with the evolution of various decomposition products in each stage. Due to their properties the novel materials can be applied as stabilizers, modifiers, fillers, matrices, 
plastics, excipiens for the specific drug delivery systems or as potential precursors for the preparation of carbon materials.

Open Access This article is distributed under the terms of the Creative Commons Attribution 4.0 International License (http:// creativecommons.org/licenses/by/4.0/), which permits unrestricted use, distribution, and reproduction in any medium, provided you give appropriate credit to the original author(s) and the source, provide a link to the Creative Commons license, and indicate if changes were made.

\section{References}

1. Ait Ali M, Allaoud S, Karim A, Roucoux A, Mortreux A (1995) Tetrahedron 6:369-370

2. Wheeler JW, Ibrahim SA, Weldon PJ (1999) Biochem Syst Ecol 27:27-32

3. Taylor WG, Schreck CE (1985) J Pharm Sci 74:534-539

4. Morris RH (2007) In: de Vries JG and Elsevier CJ (eds) The handbook of homogeneous hydrogenation. Wiley, Weinheim

5. Songkro S, Hayook N, Jaisawang J, Maneenuan D, Chuchome T, Kaewnopparat N (2012) J Incl Phenom Macrocycl Chem 72:339-355

6. Burdock GA (2005) Fenaroli's handbook of flavor ingredients. CRC Press, Cleveland

7. Alsters PL, Jary W, Nardello-Rataj V, Aubry JM (2010) Org Process Res Dev 14:259-262

8. Bauer K, Garbe D, Surburg H (2001) Common fragrance and flavor materials: preparation, properties and uses. Wiley, New York

9. Habulin M, Sabeder S, Paljevac M, Primoz ic $^{`}$ M, Knez Z (2007) J Supercrit Fluids 43:199-203

10. Croteau R (1980) Fragrance and flavor substances, D\&PS Verlag, Pattensen

11. United State Patent (1977) 5652205 Perfumes for laundry and cleaning compositions

12. United State Patent (1996) PTC/US1995/008965 Manufacture of perfumes for laundry and cleaning

13. Gildemeister E, Hoffmann FR (1913) The volatile oils. Wiley, New York
14. Melo LLMM, Pastore GM, Macedo GA (2005) Process Biochem 40:3181-3185

15. Chatterjee BKDT, Bhattacharyya DK (1999) J Am Oil Chem Soc 76:1501-1504

16. Worzakowska M (2015) Sposób otrzymywania tetraestrów zapachowych. Patent RP 221455.

17. Worzakowska M (2014) J Therm Anal Calorim 118:299-309

18. Worzakowska M (2015) J Therm Anal Calorim 121:235-243

19. Athavale V, Manjrekar N, Athawale M (2003) Biotechnol Prog 19:298-302

20. Grochowicz M, Gawdzik B (2013) J Porous Mater 20:339-349

21. Worzakowska M, Grochowicz M (2015) Carbohydr Polym 130:344-352

22. Worzakowska M (2016) J Therm Anal Calorim 124:1309-1318

23. Worzakowska M (2017) J Therm Anal Calorim. doi:10.1007/ s10973-017-6182-y

24. Lim ST, Lee JH, Shin DH, Lim HS (1999) Starch/StÓ“rke $51: 410-415$

25. Sokrates G (2001) Infrared and Raman characteristic group frequencies, tables and charts. Wiley, New York

26. https://www.nmrdb.org

27. Athawale VD, Rathi SC (1997) React Funct Polym 34:11-17

28. Fares MM, El-faqeeh AAS, Osman ME (2003) J Polym Res 10:119-125

29. Fakhru'l-Razi A, Qudsieh IYM, Yunus WMZW, Ahmad MB, Rahman MZA (2001) J Appl Polym Sci 82:1375-1381

30. Tuncel K, Ecevit K, Kesenci K, Piskin E (1996) J Polym Sci Part A 34:45-55

31. Pathania D, Sharma R (2012) Adv Mater Lett 3:136-142

32. Kaith BS, Singha AS, Grupa SK (2003) J Polym Mater 20:195-199

33. NIST Chemistry Webbook, NIST standard reference data 2011, http://webbook.nist.gov

34. Liu X, Wang Y, Yu L, Tong Z, Chen L, Liu H, Li X (2013) Starch-Starke 65:48-60

35. Liu X, Yu L, Xie F, Li M, Chen L, Li X (2010) Starch-Starke 62:139-146

36. Yu J, Gao LZ, Li XL, Wu C, Gao LL, CM Li (2016) New Carbon Mater 31:475-484

37. Zhao M, Li B, Cai JX, Liu C, McAdam KG, Zhang K (2016) Fuel Process Technol 153:43-49 